\title{
Experiment Teaching Reform and Practice of Fundamentals of Electronic Technology in CDIO Mode
}

\author{
Wenjie Zhang ${ }^{1, \mathrm{a}^{*}}$ and Jinfeng $\mathrm{Li}^{1, \mathrm{~b}}$ \\ ${ }^{1}$ Nanchang Institute of Science and Technology, Nanchang, 330108, China \\ a524892454@qq.com, b568740355@qq.com
}

Keywords: CDIO mode; Electronic Technology; Experiments Teaching; Reform

\begin{abstract}
CDIO engineering education idea is introduced firstly. The existing issues in experiment teaching of fundamentals of elec-tronic technology are analyzed secondly. After that, based on CDIO teaching mode, experiment teaching method reform on fundamen-tals of electronic technology is performed, which includes reform conditions and how to implement CDIO during a reform. At last, are-form practice result on fundamentals of electronic technology teaching is reported, which shows the students' motivation of learning e-lectronic technology is effectively excited and engineering practice ability of applying electronic technology is improved.
\end{abstract}

\section{CDIO Engineering Education Idea}

CDIO takes the life cycle of product development to product operation as the carrier, so that students can learn engineering from an active, practical and organic way. It is an engineering education model founded by Massachusetts Institute of Technology, Royal Swedish Institute of technology, Swedish University of Charles Moss industry and Linkoping University in Sweden. This educational model emphasizes that the process of teaching should train students to participate in all stages of the whole life cycle of products, processes and systems like engineers, that is, conception, design, implementation and operation. The main feature of the CDIO teaching model is that it creates two yuan learning experience that can deepen the learning technology base and practical ability, and systematically puts forward 12 standards for the ability training, comprehensive implementation and test evaluation of the operability. By the end of 2008, CDIO has 36 members. Shantou University, Jiangxi Many universities, such as the University of science and technology, the Dalian Neusoft Information Institute, and the Beijing Union University, took the lead in the CDIO reform attempt and were innovating and improving with the practice of the school.

\section{Problems in the Traditional Experimental Teaching Model}

\section{Organization and Method of Experimental Teaching Lead Students to Learn Passively}

he traditional teaching method for the basic experiment course of electronic technology is to explain the contents and requirements of the experiment. The trainees are explained in accordance with the instructors and the instructions of the experimental instruction. The teacher is responsible for solving the problems encountered in the course of the students' experiment. The biggest problem of this teaching model is the passive learning of the students. The students' experiment is only to accomplish certain experimental tasks, but can not achieve the improvement of knowledge, ability and quality. The concept of process and the experiment technology, make the students "cannot see the wood for the trees". The experimental process and methods are limited to the experimental box and test the circuit according to the requirements. There is no exploration and research, the lack of design and design of the circuit can not stimulate the students' creative consciousness and passion.

\section{Single Test Examination Method}

The experimental results of electronic technology are evaluated according to the usual experimental results, experimental reports and the end of the experiment. In order to obtain high experimental results, the students must strictly follow the experiments of the operation process and 
lack of thinking and exploration in order to achieve the experimental results. The teachers spend a lot of time and energy on evaluating the students' experimental results. The time of guidance and help is reduced accordingly. The experimental reports submitted by students are too many references to each other, which can not truly reflect the experimental results of students. There is a lot of uncertain factors for a test operation at the end of the semester, while the final experimental examination also accounts for a large proportion of the experimental results, nor can it reflect the true level of the students.

\section{Ideas on the Reform of Teaching Methods}

\section{The Conditions for the Reform of the CDIO Teaching Model}

According to the recommendation of CDIO international cooperation organization, the specific method to implement CDIO is shown in Fig 1. According to the requirement of realizing CDIO, the first condition for teaching mode reform is to require teachers to study and understand CDIO standard deeply. 12 standards are used to describe the teaching patterns of CDIO. They are the background environment, the learning effect, the integrated curriculum plan, the introduction of engineering, the experience of design and implementation, the place of engineering practice.

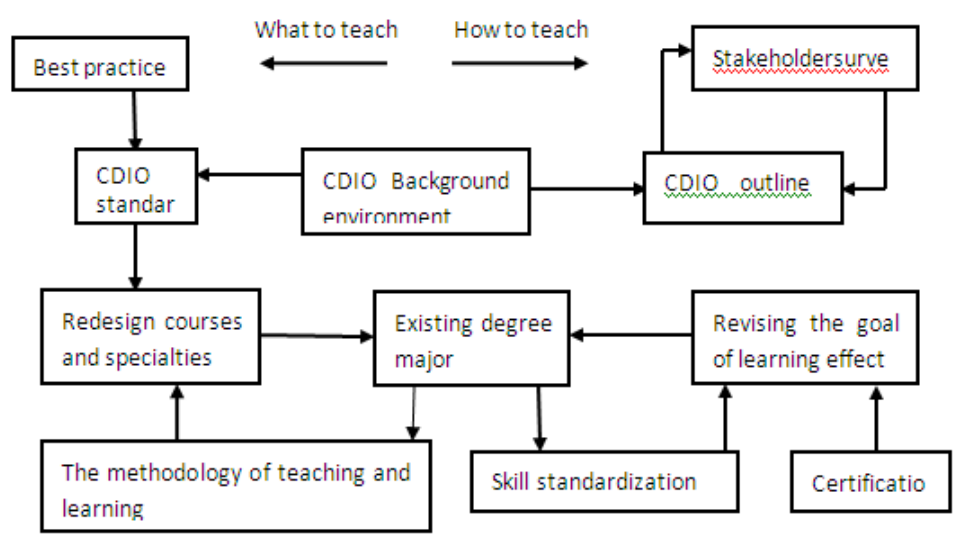

Fig 1 Method for implementing CDIO

The 12 standards are summed up in 6 aspects: professional philosophy, curriculum development plan, design and implementation experience and practice place, teaching and learning method, teacher development and assessment and evaluation. Teaching reform based on CDIO mode must follow these 12 standards. The second requirement for CDIO teaching mode reform is to conduct stakeholder surveys and formulate CDIO syllabus. As a personnel training in military academies, stakeholders are troops. As the teaching of electronic technology in military academies, we must find out what are the requirements of the army in terms of electronic technology. The basis of electronic technology as a basic course, stakeholders and professional courses, it is necessary to make clear what requirements for the basic courses of electronic technology in the course of professional courses, and to focus on the teaching of different professional students.

The third requirement for CDIO teaching mode reform is to ensure the engineering practice conditions and student learning time. The engineering practice mainly includes the open laboratory management methods, electronic components and computer and information resources. The existing conditions in some colleges and universities do not fully meet the requirements of the reform of the CDIO teaching model. The students' learning time is also a prominent contradiction in the military academies, because the students in the military colleges and universities have to do military training and political learning in addition to the course of learning.

\section{The Implementation Steps of the Reform of the CDIO Teaching Model}

The traditional experimental teaching is to set up the basic experiment and set up the comprehensive design experiment. In accordance with the requirements of the instructor and the relevant reference materials, the instructor is still a teacher centered instillation education in order to 
complete the instructor's requirements for the experiment. After the CDIO teaching model, taking the CDIO standard as the benchmark, the CDIO syllabus as the basis and the project teaching method as the traction, the comprehensive design experiment is put on the agenda from the beginning of the experiment course. Taking the CDIO syllabus (Curriculum Standard) for the electronic technology basic experiment of the Naval Engineering University as an example, the concrete implementation steps of the CDIO teaching model are divided into four stages of CDIO, as shown in Fig 2.

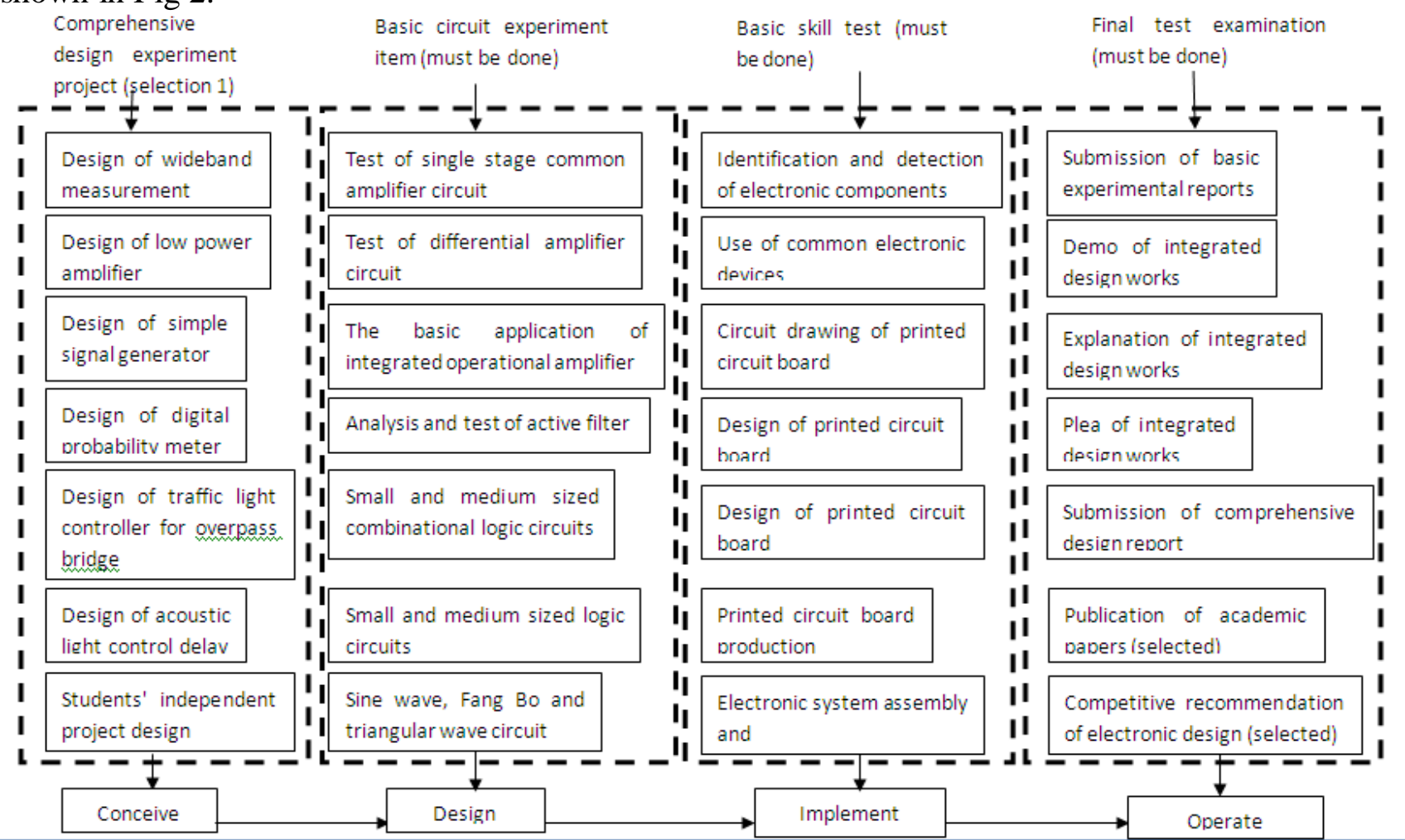

Fig 2 Implementation process of experimental teaching of electronic technology foundation under CDIO mode

Conceptual stages. The opening time of the experimental class is $2 \sim 3$ weeks after the opening of the theory class. At that time, the students knew something about the electronic system, but most of the circuit knowledge had not yet been studied. In the stage of conception, students are asked to know what to do in comprehensive design experiments, what functions to accomplish, and how to design and implement specific circuits. Students should form groups based on interest, discuss with each other, diverge thinking and create more ideas.

Design phase. At this time, students enter the theory of the circuit principles learning and start to do basic circuit experiments, students need to combine theoretical knowledge learning, basic circuit experiments and the established objectives of the design phase of the three aspects of the circuit design, side learning side design, team members should often discuss the project design program together, the teacher can help The feasibility of the aid analysis scheme. After the completion of theoretical study and the completion of basic experiments, we must confirm the final project plan.

Implementation phase. At this time, students need to learn the design and production of printed circuit boards, electronic system assembly, welding and debugging, and the design phase of the plan in printed circuit board, porous board or bakery on the material and perform functional and performance testing.

Operation stage. In order to objectively and impartially evaluate the final results of the students, the operation stage is carried out by the group as a unit, explaining the work principle, introducing the design experience and answering the questions raised by other students and teachers. In the process of defense, it is necessary to explain the tasks completed by the members in the group. Other students should evaluate the results of the group. The teacher gives the results according to 
the task situation, the actual performance of the defense and the design report submitted by the team members. The final results of the students are weighted by the results of the two parts. For projects with outstanding performance and original design, they can be recommended to participate in the National Undergraduate Electronic Design Contest and guidance to complete the publication of academic papers.

\section{Practice of Reform of Experimental Teaching Methods}

According to the conception of the reform of the basic experiment teaching mode of electronic technology under the CDIO mode, the new electronic technology basic experiment teaching mode is carried out in the 2012 level electronic science and technology specialty of the Naval Engineering University. There are 30 students in this major. All of them are from graduating high school graduates. Their overall quality is good. A lecturer and a tutor shared the experimental teaching of the class. Before the class, the CDIO concept, the CDIO standard and the CDIO syllabus were thoroughly studied, and the teaching ideas of the cadets as the center and the assistant of the teachers were established. In the first class, the students were divided into groups. The principle of the division was based on the students' own interest and the voluntary combination of the last term, and the "strong" and "weak" collocation was basically done to facilitate the study.Mutual help. Students are very active in the conception stage, envisaged a lot of interesting functions. After entering the design stage, they are limited to the limited knowledge to begin to appear, but they have realized most of the functions under the teacher's patient guidance. At the stage of realization, some problems have also been encountered, for example, in the design phase which has been verified by computer simulation on the porous plate, the actual measurement is not in conformity with the requirements. Some of the reasons are that no welding is good, and some are the problems of the components. In the defense stage, some students are shy and have poor expressive power. The whole process of practice is still more successful.

\section{Summary}

There are two enlightenments in the reform and practice of CDIO teaching mode based on electronic technology experiment.

After adopting the CDIO teaching mode, the learning requirement of students is not reduced, but increased, and students need to invest more time and energy. After the use of the CDIO teaching model, it is necessary for students to connect with their knowledge, to consult a lot of information, to think actively and actively, to communicate and cooperate with other students, and to show and explain their works to achieve good results. In the case of limited hours and time, the students need to create good conditions for the students and provide reference materials, information resources, tools and components.

The concept of some teachers has not completely changed, too much restraint to students, like to tell students that you should do so, do not really take the students as the center, learning is the student, to some extent, the enthusiasm of the students and the enthusiasm of innovation. In the practice of teaching reform in the late need to reform the concept of teachers, students to help and not for others.

\section{Acknowledgements}

This project is supported by the educational reform program of Nanchang Institute of Science and Technology in 2017. The subject number is NGJG-17-01. 


\section{Reference}

[1]Li Tong, Zhao Na. The National Excellent Course Construction of software engineering based on CDIO [J]. Computer education, 2012 (1): 14 - 19.

[2]Cao Xian, Yang Jinling, Qu Jian Guang, et al. Practice of teaching mode of "principle and method of digital mapping" based on CDIO concept [J]. Experimental science and technology, 2013, 11 (5): $113-114$.

[3]Zhang Guobin, Zhang Shujun, Liu Chuncheng, et al. The training of students' practical ability based on CDIO mode [J]. Laboratory science, 2014, 17 (1): 126127.

[4]Du Jing, Li Ying, Zhang Yanhong. Based on the concept of CDIO, "software engineering" course construction research [J]. Modern computer, 2014 (1): 49 - 50.

[5]Cui Qun, Wang Yong, Wang Keke, et al. Research and Practice on the practical teaching system of the engineering specialty of the Internet of things based on CDIO [J]. Experimental technology and management, 2013, 30 (5): 111 - 113.

[6]the construction and practice of the experimental teaching system in Colleges and Universities under the threshold of Tao Yuwei, Xie Aijuan and Zhang Baoling. [J]. Education and teaching research, 2013, 27 (10): 96 - 97.

[7]Li Jinping, Liu Yuansheng. Research and course design of CDIO training system for electronic information en gineering major [M]. Beijing: Beijing Jiaotong University press, 2013: 595 - 560.

[8]Zhou Dahua, Chen Shaochang, Zhan Guoqiang. Research on the experimental teaching method of single chip microcomputer based on CDIO mode [C] / Wang Weiguo. Thesis collection of the tenth Academic Symposium on laboratory construction and development of military academies. Beijing: National Defense Industry Press 2012:380.

[9]Yongfeng Zheng. Research on project driven curriculum system of Mechatronics major in Higher Vocational Education[D]. Zhejiang Normal University, 2014.05.

[10] Caibing $\mathrm{Wu}$. Tungsten resource development project driving practice teaching course[M]. Metallurgical industry press, 2016.08. 